\title{
Philosophical Aesthetics and Neuroaesthetics: A Common Future?
}

\author{
Bruno Trentini, "Philosophical Aesthetics and Neuroaesthetics: A Common Future?”, \\ Aesthetics and Neurosciences, Zoï Kapoula and Marine Vernet (Eds), Springer, 20I6, chapt. 7, p. 3OI-3I I.
}

\begin{abstract}
The future of the art/science relationship does not only concern the field of artistic creation, but also the field of aesthetic experience. In fact, whereas aesthetics has existed as a philosophical discipline since the I8th century, more and more scientific experimental works study aesthetic experience. Philosophical aesthetics now shares its object of study with what is often called neuroaesthetics. The aim of this chapter is to shape a common vision enabling philosophical aesthetics and neuroaesthetics to pool their results and their tools so that the research world does not suffer from a regrettable scission in the field of theory of artistic theory. Indeed, aesthetics seems to have a lot to gain from physiological studies dealing, on the one hand, with the capacity of cognitive processes to adapt to non-routine situations and, on the other hand, with the capacity of these adaptations to be felt by individuals.
\end{abstract}

It does not seem possible to isolate cognitive processes that are specific to aesthetic experiences. For instance, perception processes are very frequently involved in the experience of a work of art, and are systematically involved in the reception of an anamorphosis by Felice Varini or an immersive work by Ann Veronica Janssens. Premotor and motor processes seem necessary to mentally reconstruct the poietic gesture in front of a work by Jackson Pollock, or to interact with a work by Maurice Benayoun. The list could go on and on. It would besides be very surprising to find a kind of cognitive process that works of art cannot activate and it is easy to think about works of art that each mobilizes many kinds of cognitive processes. The understanding of each process in isolation is not yet sufficient to understand what aesthetic experience is.

These observations highlight the fact that aesthetic experience is integrative, that is to say that it involves many levels of cognition, and that it cannot be reduced to an atomic behavior; in other words: it is complex. Regarding the issue of naturalization of aesthetics, this complexity can be interpreted in two different ways: either we consider that the aesthetician cannot dispense with the understanding of the cognitive processes involved in aesthetic experience, or we consider that any attempt at naturalization is detrimental to aesthetics, because the mere fact of trying to naturalize experiences that are so complex would inevitably lead to a harmful reduction of the field. Besides, regardless of whether naturalization is desirable or not, we can first wonder if this approach is even possible. Yet, if we define naturalization as a scientific approach aiming at finding observables that can give account for issues that were initially not related with physiology - that were not embodied -, the complexity of aesthetic experience makes it almost impossible to find relevant observables. This chapter notably aims at defining the observables which would be interesting to study in order to naturalize aesthetics. Of course, the choice of the observables and the choice of the concepts of philosophical aesthetics to be naturalized will impact the progression of the field: do we aim at naturalizing an aesthetic category like the beautiful or the sublime, or at naturalizing the specificity of any aesthetic experience? Of course, various possibilities exist and the mere fact of making a choice will necessarily tend to freeze and narrow the field down. However, in order to undertake the most relevant naturalization, it would be better if the naturalization of aesthetic experience did not shift the key issues of the field. As a consequence, the question of knowing if naturalization is desirable and the question of knowing if it is possible can be dealt with together. We should besides not forget that

I. This chapter is the translation of my French paper: Trentini B (20I5) Quelle naturalisation pour quelle esthétique ? (Which Naturalization for Which Aesthetics?, Nouvelle revue d'esthétique $\mathrm{n}^{\circ}$ I5, p. 59-67. 
aesthetics was at the origin anchored in a physiological and even a psychophysical framework, and that contemporary aesthetics has developed from this framework of scientific naturalism. If the question of naturalization is now once again taking center stage, it is above all as a result of the emergence of cognitive science, which have modified the way we comprehend the relationship between human beings and their environment. Cognitive science notably enable us to think about sensitivity and intelligibility in another way, to think about the relationships between these two notions, and even to think without using these labels that arbitrarily create a distinction where maybe none is required. One main difficulty of the aesthetician indeed lies in the articulation of sensation and knowledge, perception and intellection.

Since naturalist investigations are de facto being carried out, the most important point to tackle the issue of the naturalization of aesthetics seems to be to figure out which naturalization is possible for the aesthetics that we wish. Thus, this chapter is intended both for the supporters of naturalization and for its firmest opponents, both for philosophers and for scientists. If choosing a specific label for the aesthetics proposed in this chapter was required, embodied aesthetics would best fit. Embodied aesthetics is the extension of embodied cognition, a philosophical trend proposed by Francisco Varela notably following the reading of the phenomenology of Merleau-Ponty: sensations, perceptions but also body and physiology are thus thought to be the main actors of aesthetic experience.

The first part of this article provides a presentation of the main experimental and epistemological pitfalls encountered in neuroaesthetical studies on the beautiful and pleasure. Not only is the study of the beautiful cut off from a considerable part of the artistic reality - which could be a conjectural and accidental problem - but it also presents difficulties that are not encountered in the study of the other aesthetic category defined in the I8th century, the sublime. The second part of this article puts emphasis on the sublime, showing that even though very few neuroaestheticians have worked on it until now, its naturalization is far more advanced. One of the best advantages of the sublime is that it involves cognitive processes that are quite well understood or at least much studied. We will finally discuss the resulting question of knowing whether it would be better to naturalize aesthetics or to encourage philosophical aestheticians to seize naturalized studies which do not necessarily deal with aesthetics.

Naturalization of the Experience of the Beautiful: Methodological and Epistemological Pitfalls Even if the first studies carried out by Plato and Aristotle about artistic creation did not tackle the question of art by focusing on the beautiful but by focusing on imitation, the beautiful has prevailed as an artistic value, to such an extent that Hegel defined aesthetics as the science of fine art. If the beautiful has become the category which is the most (widely) studied by neuroaestheticians, this is of course because it is the most common and classical label. But this may also be because it seems easy to justify this aesthetic approach with respect to the Neo-Darwinist theories. For example, sexual attraction can be thought to be the substrate on which the beautiful has developed. Surprising as it may seem, this hypothesis was more or less already formulated in The Symposium by Plato, was put forward two millennia later by Nietzsche (Nietzsche I889), and is nowadays defended by some researchers (Grammer et al). In other studies, a link between aesthetic experience and the prey/predator relationship is proposed (Smith 2005). These studies bet on a behavior that has increased the fitness of the individual. This hypothesis is deemed questionable since it explains aesthetic behavior only by the pleasure that is generated, without any consideration about the processes that generate this pleasure: according to Denis Dutton, this idea is as simplistic as thinking that a pleasure pill would be equivalent to aesthetic experience (Dutton 2009).

It is yet important not to confuse, on the one hand, the rooting of aesthetic behavior in the theory of evolution with, on the other hand, the naturalization of aesthetics, which consists in defining relevant observables. While the first is for the moment purely speculative, the second is an approach giving rise to practical experiments, which we can precisely discuss. There seems to be an epistemological problem which is inherent to the works dealing with the beautiful in art. This problem comes from the term 
"the beautiful" itself, which suffers from a strong socio-cultural bias. However, while he was aware of the subjectivity of the judgment of taste, the father of neuroaesthetics, Semir Zeki, chose to work on the beautiful. He is in that way consistent with a major philosophical tradition, since his more precise goal is to manage to naturalize the free play of faculties, which Kant supposed to be the major characteristic of the beautiful (Kant I790). Naturalization thus consists in finding an invariant that would systematically come into play when individuals feel a pleasure generated by an object that they find beautiful, and which would not or almost not hardly occur otherwise, in order to be able to observe the free play of faculties. Zeki searched for this invariant in cerebral activity, in a given cerebral area. In that sense, he assumed the existence of a "module" of the beautiful. We will not discuss this hypothesis, but we will discuss some experiments aiming at testing it, more precisely the experiments described in the paper of Ishizu and Zeki (Ishizu and Zeki 2OII). It is worth noting that when Zeki and Ishizu studied individuals who are confronted with a work of art, they took care not to impose to the subjects an object that they, the experimenters, would found beautiful. They indeed asked the subjects to evaluate the beauty of the objects that were submitted on a scale from I to 9, in order to correct the bias due to differences in taste. Afterwards, Ishizu and Zeki tried to identify the specificity of the cerebral activity of the individuals while they were apprehending the objects that they, the subjects, had themselves judged as beautiful.

We cannot deny the fact that it is necessary in the design of the experiment to ask the individuals which objects they consider as beautiful, in order to take into account the taste of each of them. Nevertheless, this caution relies on a problematic introspection. Indeed, the beautiful that Zeki aimed at subjectively describing is very precise: the will of characterizing the neural bases of the experience of the beautiful presupposes the distinction between the beautiful and other positive categories like the agreeable or the sublime. Yet, the problem is that it is not wise to consider that the subjects who are studied by this neuroaesthetics are able to distin-

2. This hypothesis is inspired by Jerry Fodor's research on the modularity of mind. guish between these different positive aesthetic categories: many people use the term "beautiful" to characterize a rough ocean under a threatening sky, whereas they must activate cognitive processes that are very different from the ones they activate when they look at a "beautiful" bunch of tulips. This problem remains unaddressed by neuroaesthetics. The design of the experiments which focus on the beautiful does not usually take into account the different aesthetic categories (Cela-Conde et al. 20I3; Cela-Conde et al. 2004; Zeki I999) - and it will probably remain difficult to take these categories into account with non-expert subjects. It would thus be preferable to carry out experiments aiming at the naturalization of aesthetics without using a sociocultural label as complicated as "beautiful". Unfortunately, asking for an introspection about aesthetic categories which are less used - and which are thus not mastered by everyone - would equally distort the results. The same criticism applies to the studies in which individuals are asked to classify works of art according to their aesthetic preferences (Vartanian and Goel 2004); the adjective "aesthetic" has had, in the everyday language, in English as well as in French, a meaning which is very different from the philosophical and neuroscientifical meaning which is supposed to be studied in these works. Thus, not only should not art be reduced to the beautiful, but another pitfall should also be avoided: aesthetic experience should not be reduced to pleasure. Even if we accept that all every aesthetic experience gives rise to pleasure, a major stake is to understand the specificity of the pleasure of aesthetic experience. Once again, focusing on the category of the beautiful proves to be problematic: it wrongly suggests that, as soon as an aesthetic experience is unpleasant at any level, it cannot bring satisfaction. Some studies thus limit aesthetics to the beautiful, to the neutral and to the ugly (Tommaso et al. 2008), or to an opposition between positive and negative values (Munar and al. 20I2; Kreplin and Fairclough 20I3; Lang et al. I993). A considerable experimental bias seems to occur here to the extent that these approaches go against many behaviors performed in front of works of art which exploit an attraction/repulsion relationship, as in the case of the category of the sublime. 


\section{The Sublime Enables}

\section{a Less Problematic Naturalization}

Maybe by default, or perhaps because we have the means to do so - in a nutshell, a priori without any objective reason - pleasure and the beautiful have been studied. They are important in aesthetic experience, but all pleasure is not aesthetic. It is important not to confuse the beautiful, aesthetics and art: when it comes to building a neuroaesthetics that aims at becoming a theory of art, one of the main risks is to study the beautiful as if it were a synonymous for art. Only by opening up the cognitive investigations to aesthetic values other than the beautiful can we maintain the crucial interdisciplinary dialog between neuroscientists and both classical and contemporary philosophers of art.

The works of naturalization that focus on the beautiful run the risk of shifting the principle of the field, or even of diluting it in researches that cannot give account for the diversity of aesthetic experiences. It is not possible to study a single pleasure at a hormonal, neuronal or even behavioral level, since the complexity and the integrativity of aesthetic experience makes it possible for the spectator to be satisfied with a work that is, at a physiological level, unpleasant. This case is the one which is described by Burke, Kant, Hegel or Schiller in their works on the sublime. The sublime implies unpleasure, fear (or representation of fear), but comes to pleasure. Reductionist naturalist researchers would tell us that it is neither possible to enjoy the sublime, nor the vertigo, nor the imbalance felt at the top of the Tower of Pisa: indeed, their studies would highlight the fact that individuals wince, that beads of sweats form on their foreheads, that they physiologically feel emotions that fall into the category of negative emotions ${ }^{3}$. However, despite all this, some would be satisfied. Let there be no mistake, we do not intend to say that such empirical studies would refute introspection; on the contrary we intend to say that they would lead to propose a theory that would be refuted by the studied system itself, that is to say the set of aesthetic experiences. Thus, trying to naturalize the approbation of the spectator who is confronted with a work of art not only is not a question

3. This criticism can also more generally apply to studies that try to describe aesthetic experience as an ability which would be selected for itsely by evolution. of aesthetics anymore, but gives also rise to the risk of grafting an over-simplified determinism onto an experience which involves too many parameters to be modeled by a reductionist approach.

Anjan Chatterjee hypothesized that the lack of interest of research toward the sublime can be explained by the limited data available about the cognitive processes that are involved in the behavior linked with the sublime. He mentioned the metaphor of a person who would search for his dropped coin under the light of a street-lamp because it would be the only place which would be lit, even if he would not have lost it at that place (Chatterjee 20IO). Indeed, the sublime is not studied enough in neuroscience, but this metaphor does not seem to bring a satisfactory explanation. In fact, even if the label "the sublime" is poorly used is neuroscience, the experiences linked with the sublime do involve many processes that are widely studied. The processes involved in the aesthetic experience of the sublime, for instance postural imbalance or vertigo, are indeed abundantly studied - because postural imbalance is also associated with many pathological behaviors. There could be an interplay between the study of pathological imbalance in a routine context and the study of the imbalance of a healthy individual in an artistic context: artistic objects indeed imply a considerable particularity in the relationship between individuals and their environment. Imbalance at the levels of posture and of the vestibular system would constitute a relevant observable to naturalize the sublime. What is more, the specificity of the sublime lies in the satisfaction that is taken in an unpleasant situation: fear, which is generally classified as a negative emotion (Ekman I992), becomes a source of pleasure. Regarding this subject, we can also find an abundant literature about emotions, mainly about negative emotions like fear. It is also quite easy to rationalize fear in light of the theory of evolution: it acts as an alarm to draw the attention of the individual to a danger he or she should avoid. In other words, the aesthetic experiences that can be described as sublime already benefit from real scientific investigations in the field of cognitive science and in the trend of naturalization.

It would be a mistake to believe that neuroaesthetics focuses on the beautiful because the means 
that are available to study aesthetic experience would not enable to study another aesthetic category. There have besides been some works in cognitive aesthetics dealing with the sublime in general and the situation of imbalance in particular (Noë 200I). These studies have given rise to few experiments, simply because the works of art that were used were large sculptures, which made the practical implementation of the experiments challenging 4 . Yet, many bidimensional works can have an impact on the postural equilibrium of the spectator and could constitute a promising paradigmatic case study. Contemplation irrationnelle, a work created in 2003 by Philippe Ramette, is in that sense particularly interesting. In this photograph, we can see a person who is apparently sitting at the edge of a quite impressive precipice. We can quickly realize that this photograph is actually a quite commonplace view that has been rotated one quarter-turn, so that the great skyline irremediably becomes an abyss. The road that is winding between small hills becomes a path that is almost vertical. However, the awareness that the landscape has been rotated is not sufficient to suppress the illusion of the precipice because the person that we see seems to be sitting in the correct orientation: his thighs appear horizontal, his back vertical. It would be interesting to study to what extent the perception of this photograph by an individual that would be in front of it, preferentially standing up, stimulates his or her vestibular system and (her) posture. Some studies dealing with the contagion of vertigo suggest that the fact of watching another person who is in a situation of imbalance can lead to a modification of one's own balance. We could thus speculate that imbalance could arise from perceptual processes which, under the influence of visual discordances linked with verticality, do not provide conscience with a steady perception, but with a perception that frequently oscillates between a photograph that would or would not have been rotated. Aesthetic experience thus seems stimulated by various elements, notably the tendency for empathy, vertigo - both caused by real risks or by the illusion of risks -, or the possibility of bistable perception. It could without doubt be

4. We notably think about Clara-Clara by Richard Serra, which is an example that Alva Noë took. Since it is a monumental sculpture, any study should only be done in situ. possible to list more elements, and it could then be even more difficult to know which one would be specific to the aesthetic experience which is at stake, if we suppose that this question even has a meaning. Therefore, it may be more interesting for aesthetics to study the cognitive processes involved in aesthetic experiences without trying to give account for the particularity of one aesthetic category or another.

\section{Upstream and Downstream Aesthetic Categories}

It does not seem possible to naturalize aesthetics, but it is interesting to naturalize the routine cognitive processes that are involved, in a non-routine manner, in aesthetic experiences. If only for the comparison between the beautiful and the sublime, we realize that studying the specificity of one will not enable to understand that of the other: the beautiful and the sublime are very different as far as the cognitive processes and the link with the theory of evolution we could draw are respectively concerned. Indeed, the beautiful is often considered as a derivation of an acquired behavior, but it is harder to explain the pleasure that the individual takes in a context that stimulates a state of alarm from a physiological point of view. As we have highlighted from the introduction of this chapter, aesthetic experiences involve numerous cognitive processes. Since it does appear that one of them is not more particular than another, we could hypothesize that aesthetic experience emerges from a common way of using cognitive processes. Regarding this hypothesis, we can detect a constant in the philosophical history of aesthetics: aesthetic experience is induced by a sensitive awareness of our own cognitive processes even though our attention focus on the outside world. This statement is a contemporary and generalized rephrasing of the idea that the awareness through the sensitivity of the free play of faculties is a reflective judgment that Kant supposed to be at the basis of the beautiful ${ }^{5}$ (Kant I790). This hypoth-

5. Semir Zeki seized the concept of the free play of the faculties to make it the cornerstone of his naturalization at the neural level; it seems to us that his modularist approach - as defined by Fodor - cannot enable to understand aesthetic experience. In fact, the cognitive fluence that he studied is specific to the beauty. We thus loose the specificity of reflective judgment to only keep fluence. Not only this study 
esis is in keeping with the integrative idea that aesthetic experience involves a split attention (focused on oneself and on the world), or involves a self-reference to one's own mental processes (Vessel et al. 20I2; 20I3). We adopt such a characterization of aesthetic experience as a general working hypothesis because it gives account for the possibility that aesthetic experience can involve numerous cognitive processes: aesthetic experience is a sensation induced by the way cognitive processes, whatever they may be, adapt as successfully as they can to non-routine and highly cultural situations. Thus, the most convincing way of trying to naturalize upstream aesthetic categories like the beautiful and the sublime is to find the observables that indicate the adaptability of cognitive processes, i.e. the reconfiguration of perception. Naturalizing reflective judgment would be a better way to observe aesthetic experience. Nevertheless, the question of knowing whether this knowledge will help the aesthetician to give a better account of artistic experiences remains open: naturalizing reflective judgment is a response to a speculative will of understanding aesthetics in its most abstract issue (Trentini 20I4). On the contrary, in order to build an aesthetics that is able to give account of artistic experience downstream aesthetic categories, it would be more interesting to understand the steps leading to reflective judgment rather than reflective judgment itself. To translate the words of the introduction of Naturaliser l'esthétique written by Jacques Morizot: "the challenge we have to take up is to understand how routine mechanisms are able to generate a non-routine vision"(Morizot 2OI4). It could be tempting to hypothesize that the understanding of these routine mechanisms would not bring anything new to the understanding of aesthetics, but aesthetic experience can only emerge from breaking out routine. Because the experience is non-routine, cognitive processes must adapt to a new configuration; because they must adapt in a non-routine way, a particular feeling emerges from their adaptation. In that sense, a com-

cannot enable to establish a philosophy of art, but it also fails to pave the way for a generalization of the beauty on the other aesthetic experiences.

6. "Le défi à relever est de comprendre comment des mécanismes de routine sont en mesure d'engendrer une vision qui ne l'est pas." plete rupture with the evolutionist theories is not desirable: we have to understand how cognitive processes have adapted to the environment at the scale of evolution and how they can adapt at the scale of the individual - by being flexible or plastic -, but we should not globally consider aesthetic experience as a selected or a counter-selected ability. We should consider aesthetic experience as involving abilities that are acquired both through culture and by evolution.

\section{Conclusion}

If we were to put forward a particular skill of the aesthetician - and probably of the art critic as well we could mention the ability of making a singular experience communicable, and as a consequence the ability of conducting a good introspection, that is to say the ability of correctly grasping what is going on in their bodies, at the level of their organs, of their senses, and the ability of linking as accurately as possible these sensations to the multiple thoughts that went through their minds. This undertaking is of course not infallible, and we can suppose that the more relevant the introspection, the easier the communicability. Since we are dealing with introspection, I allow myself to speak in my name, about a personal aesthetic experience.

I discovered the works by Marcius Galan at the White Cube, gallery in London, in the summer of 20I3, and I once again saw one of these works in the exhibition Inside at the Palais de Tokyo in Paris in the winter of 20I4. Despite my research between these two moments, for instance about the way in which perception can generate the illusion of a surface where there is none, about the interpretation of the variation of colors that the presence of a glass plate would have caused, I felt an intense experience on both occasions. In other words, even if I was aware of the cognitive processes that were involved to create the illusion, the illusion still persisted. Thus, I do not think that the naturalization of aesthetics can weaken aesthetic experience - nor can it dictate aesthetic experience, since the understanding of the processes do not necessarily make a work pleasant to someone who did not like it in the first place. However, by putting forward the coupling between perception and action, I can make the wish of going through the intangible surface communica- 
ble and this is precisely what I did at the Palais de Tokyo: I waited for people to enter the room and I threw myself into the virtual window. Against all odds, I did not feel at ease. It may seem ridiculous, but my body was put into a state of alert: I was presumably afraid of hitting the glass plate. My cognitive processes apparently reacted as if the glass plate had been true. I thought that this moment was particularly interesting, and particularly promising as regards the theory of embodied aesthetics.

Sometimes, in front of a work of art, I have the intuition that one thing or another has occurred in me and that my perception has adapted in one way or another, for one reason or another. If convincing experiments that clearly refute my hypothesis have been carried out, I do not want to trust my introspection to use it to comment on the work. If on the contrary experiments of naturalization go in the same direction as my introspection, I feel comforted in my view. In other words, naturalization of cognitive processes, even apart from aesthetic experience, represent clear benchmarks in my research, which help to hold back a misleading introspection or to clarify a relevant but too confused introspection. Thus, knowing that experiments have shown that most people feel unbalanced while watching a funambulist nourishes my research on Philippe Ramette. Knowing that experiments dealing with disown (Guterstam and Ehrsson 2OI2) - which is the feeling of not belonging to one's own body were put forward nourishes my research on the works by Ann Veronica Jannsens. The list could go on and on, yet, further research would still be required in order to obtain relevant data to carry out a work of embodied aesthetics dealing for example with conceptual art. I am nevertheless perfectly prone to believe that such data can be obtained.

These few elements having been established, aesthetics seems to have a lot to gain from physiological studies dealing, on the one hand, with the capacity of cognitive processes to adapt and, on the other hand, with the capacity of these adaptations to be felt by individuals. It is to our mind at these two levels that naturalization can prove to be beneficial to aesthetics.

\section{References}

Cela-Conde C et al. (2004) Activation of the prefrontal cortex in the human visual aesthetic perception. Proceedings of the National Academy of Sciences USA, IOI:632I-6325

Cela-Conde $\mathrm{C}$ et al. (20I3) Dynamics of brain networks in the aesthetic appreciation. PNAS, vol.I08, supp.2:I0454-I046I

Chatterjee A (20IO) Neuroaesthetics: A Coming of Age Story. Journal of Cognitive Neuroscience, 23-I:53-62

Dutton D (2009) The Art Instinct. Steven Pinker, New York

Ekman P (I992) An argument for basic emotions. Cognition and emotion 6:I69-200

Grammer K et al. (2003) Darwinian aesthetics: sexual selection and the biology of beauty. Biological Reviews, vol.78, 3:385407

Guterstam A and Ehrsson HH (20I2) Disowning one's seen real body during an out-of-body illusion. Consciousness and Cognition. doi:IO.IOI6/j.concog.20I2.0I.0I8

Ishizu T and Zeki S (2OII) Toward a brain-based theory of beauty. PLoS One 6:e2I 852 doi:IO.I37I/journal.pone.0O2I 852 Kant I (I790) Critique of Judgment

Kreplin U and Fairclough SH (2013) Activation of the rostromedial prefrontal cortex during the experience of positive emotion in the context of esthetic experience. An fNIRS study. Frontiers in Human Neuroscience, vol.7, art.879 Lang PJ et al. (I993) Looking at pictures: affective, facial, visceral and behavioral reactions. Psychophysiology 30:26I273

Morizot J (ed) Naturaliser l'esthétique ? Questions et enjeux d'un programme philosophique. PUR, Rennes

Munar E et al. (2OI2) Lateral Orbitofrontal Cortex Involvement in Initial Negative Aesthetic Impression Formation. PLoS ONE 7(6): e38I52. doi:IO.I37I/journal.pone.0038I 52

Nietzsche F (I889), Twilight of the Idols

Noë A (200I) Experience and experiment in art. Journal of Consciousness Studies, vol. $7, \mathrm{n}^{\circ}$ 8-9

Smith CUM (2005) Evolutionary neurobiology and aesthetics. Perspect Biol Med, 48(I):I7-30

de Tommaso M et al. (2008) Influence of aesthetic perception on visual event-related potentials. Consciousness and Cognition, I7:933-945

Trentini B (20I4) Peut-on faire une esthétique incarnée du jugement réfléchissant?. In: Morizot J (ed) Naturaliser l'esthétique? Questions et enjeux d'un programme philosophique. PUR, Rennes

Vartanian O and Goel V (2004) Neuroanatomical correlates of aesthetic preference for paintings. Neuroreport 15:893-897

Vessel E et al. (20I2) The brain on art: intense aesthetic experience activates the default mode network. Frontiers in Human Neuroscience, vol.6, art.66

Vessel E et al. (2013) Art reaches within: aesthetic experience, the self and the default mode network. Frontiers in Human Neuroscience, vol.7, art.258

Zeki S (1999) Art and the brain. Journal of Consciousness Studies, Volume 6, Numbers 6-7:76-96.

Bruno TRENTINI 